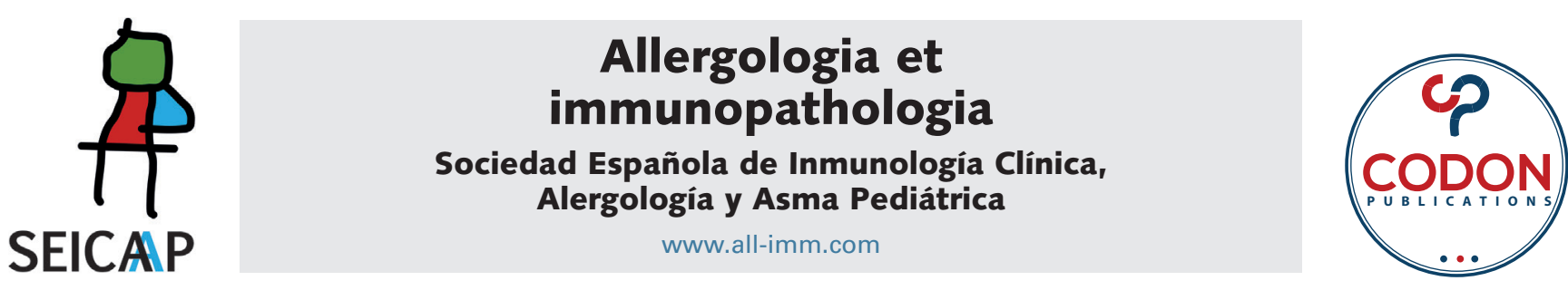

CASE REPORT

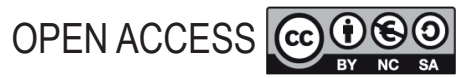

\title{
An unusual case of food protein-induced enterocolitis syndrome due to zucchini
}

\author{
Alberto García de la Fuente ${ }^{a}$, Victoria Fuentes-Aparicio ${ }^{\mathrm{a}, \mathrm{b}}$, Sonsoles Infante ${ }^{\mathrm{a}, \mathrm{b} *}$
}

aPaediatric Allergy Unit, Hospital General Universitario Gregorio Marañón, Madrid, Spain

${ }^{b}$ Gregorio Marañón Health Research Institute (IiSGM), Madrid, Spain

Received 3 June 2021; Accepted 2 September 2021

Available online 1 November 2021

\section{KEYWORDS}

food protein-

induced enterocolitis

syndrome;

FPIES;

gastrointestinal food

allergy;

non-lgE-mediated

food allergy;

zucchini

\begin{abstract}
Background: Food protein-induced enterocolitis syndrome (FPIES) is a non-lgE-mediated food allergy characterized by gastrointestinal symptoms, mainly protracted and delayed vomiting. Diagnosis is based on clinical history, and it can be challenging as symptoms are delayed and the causative food is often not very suspicious.

Objective: This case report highlights the importance of having a high degree of suspicion to reach a correct diagnosis.

Materials and methods: We report an unusual case of FPIES due to zucchini. During the follow-up. Two oral food challenges (OFC) were carried out to evaluate tolerance to the food involved.

Results: The first OFC was positive and in the second the child tolerated the food without problems.

Conclusions: In this case, the OFC was essential to identify the offending food and to verify that the child had overcome the disease.

(c) 2021 Codon Publications. Published by Codon Publications.
\end{abstract}

*Corresponding author: Sonsoles Infante, MD, PhD, Pediatric Allergy Unit, Hospital General Universitario Gregorio Marañón, O’Donnell 48, 28009 Madrid, Spain. Email address: sonsoles.infante@salud.madrid.org 
Food protein-induced enterocolitis syndrome (FPIES) is a non-immunoglobulin E (IgE)-mediated food allergy, with onset commonly observed during childhood. It is characterized by recurrent delayed vomiting, diarrhea, lethargy, and hypotension, and could progress to a state of dehydration and hypovolemic shock. The symptoms begin 1-4 $\mathrm{h}$ after the ingestion of offending food. ${ }^{1}$

Any food could be a potential trigger of FPIES; however, some foods are more prevalent than others, and there are important geographical differences. Thus, the most frequent offending foods are cow's milk (CM) and soy. Among solid foods, grains (rice and oat), egg, and specially fish, in the Mediterranean area, have been identified as the most important triggers of FPIES. ${ }^{2}$

Regarding vegetables, excluding grains, they are an unusual cause of FPIES in most countries. An FPIES study group reported that only $8 \%$ of FPIES are triggered by vegetables in an Australian cohort. ${ }^{3}$ In Europe, vegetableinduced FPIES seems to be exceptional, with most cases related to $\mathrm{CM}$ and fish. ${ }^{4}$ Vázquez-Ortiz et al. ${ }^{5}$ reported 81 Spanish children with acute FPIES but no case of FPIES was recorded due to oats, wheat, soy, fruits, or vegetables. In the United Kingdom, Ludman et al. ${ }^{6}$ reported FPIES due to vegetables in less than $6 \%$ of their population, most of them being related to grains and fruits.

Hence, it is important to notice that most vegetables are a rare, sometimes even exceptional, cause of FPIES in most geographical areas, especially in Europe. Here, we report a case of a zucchini-induced FPIES in a South European patient.

A 6-month-old child was attended at the pediatric emergency room of our hospital with repetitive vomiting, pallor, and lethargy $3 \mathrm{~h}$ after eating mashed potatoes, carrot, zucchini, and onion. The complementary feeding took place 3 days prior, and he had tolerated mashed potatoes and carrot as well as gluten-free cereals. Blood tests performed had the following results: $8.33 \mathrm{~g} / \mathrm{dL}$ hemoglobin, $18000 / \mu \mathrm{L}$ leukocytes with $6900 / \mu \mathrm{L}$ neutrophils, $8400 / \mu \mathrm{L}$ lymphocytes, and $1900 / \mu \mathrm{L}$ eosinophils, and a C-reactive protein (CRP) of $<0.1 \mathrm{mg} / \mathrm{dL}$. He had no fever. He received treatment with ondansetron and intravenous fluids repositioning. Finally, he was admitted to hospital.

The evolution was favorable. Symptoms disappeared and the white blood cell count was normal within $24 \mathrm{~h}$. Stool culture was negative for bacteria, rotavirus, and adenovirus. Once the infectious cause was ruled out, our allergy service team was consulted.

At the time of evaluation, the patient was asymptomatic and was again receiving breast-feeding. An allergy workup study was performed, revealing negative skin-prick tests for both extracts and samples of onion and zucchini as well as a negative prick-to-prick test for zucchini. A total IgE of $13.4 \mathrm{kU} / \mathrm{L}$ was obtained, with specific IgE for "Allium cepa" (onion) as $0.01 \mathrm{kU} / \mathrm{L}$ and for "Cucurbita pepo" (pumpkin) as $0.01 \mathrm{kU} / \mathrm{L}$. Specific IgE for zucchini was not performed as it was not available in the hospital. Potatoes, carrot, and onion were introduced in diet with good tolerance under physician's supervision in our outpatient hospital. Although zucchini is not a prevalent cause of
FPIES in our area, it has been considered a moderate-risk weaning food by the international consensus guidelines for the diagnosis and management of FPIES. ${ }^{7}$ As the child had tolerated other implicated foods, a zucchini-free diet was recommended.

When the child was 18 months old, an oral food challenge (OFC) with zucchini was performed. After $4 \mathrm{~h}$ of taking the whole zucchini diet, the child developed repetitive vomiting and diarrhea and required immediate intervention at the pediatric emergency room. Hospital admission was not necessary this time as he tolerated oral rehydration without any further vomiting. This time no blood tests were performed, and he was discharged after few hours of observation. At the age of 3 years, as he had not presented new episodes, a new OFC following our protocol was carried out. This time, the child tolerated 25\% (25 g) of zucchini on the first day, followed by the intake of total allocation (100 g) after $48 \mathrm{~h}$. Finally, on this occasion he tolerated the total allocation of mashed zucchini without adverse symptoms.

Food protein-induced enterocolitis syndrome is considered a rare but emerging illness. Its diagnosis remains elusive, even more so when the offending food is not commonly implied in this syndrome or there are important geographical differences, as happens with vegetables in Australia and Europe. Recently, sesame, although traditionally known for its importance in IgE-mediated food allergy in the United States, has been described as the offending food in case of five children in Israel. ${ }^{8}$ Such reports suggest that any food is capable of triggering FPIES, and therefore a high degree of suspicion is required.

New biomarkers are being searched to detect FPIES. Regarding blood cell count, a relative degree of leukocytosis and neutrophilia, as determined in the present patient, was described in the above-mentioned patients as well, ${ }^{9}$ and an ANC of $\geq 1500$ neutrophils/ $\mu \mathrm{L}$ is considered a minor diagnostic criteria for the interpretation of OFCs. ${ }^{7}$ C-reactive protein tends to be either normal or mildly elevated. ${ }^{10}$

In our patient, an OFC was performed as it is still considered the gold standard for diagnosis. ${ }^{2}$ OFC was not only necessary to confirm the diagnosis but also to assess whether FPIES had outgrown in our patient.

Finally, as this case has shown, any food is capable of inducing FPIES. Therefore, it is extremely important that, regardless of geographical differences, any food should be considered as a possible causative agent, and diagnosis could only be reached if it is preceded by a high degree of suspicion and awareness.

\section{Funding}

Authors did not receive any funding for this study.

\section{Conflict of interest}

The authors have no conflicts of interest to declare. 


\section{References}

1. Feuille E, Nowak-Wegrzyn A. Medical algorithms: Recognizing and treating food protein-induced enterocolitis syndrome. Allergy. 2019;74:2019-22. https://doi.org/10.1111/all.13857

2. ADDIN Mendeley Bibliography CSL_BIBLIOGRAPHY Agyemang A, Nowak-Wegrzyn A. Food protein-induced enterocolitis syndrome: A comprehensive review. Clin Rev Allergy Immunol. 2019;57:261-71. https://doi.org/10.1007/s12016-018-8722-z

3. Mehr S, Frith K, Barnes EH, Campbell D. Food protein-induced enterocolitis syndrome in Australia: A population-based study, 2012-2014. J Allergy Clin Immunol. 2017;140:1323-30. https:// doi.org/10.1016/j.jaci.2017.03.027

4. Vila L, García V, Rial MJ, Novoa E, Cacharron T. Fish is a major trigger of solid food protein-induced enterocolitis syndrome in Spanish children. J Allergy Clin Immunol Pract. 2015;3:621-3. https://doi.org/10.1016/j.jaip.2015.03.006

5. Vázquez-Ortiz $M$, Machinena $A$, Dominguez 0 , Alvaro $M$, Calvo-Campoverde K, Giner MT, et al. Food protein-induced enterocolitis syndrome to fish and egg usually resolves by age 5 years in Spanish children. J Allergy Clin Immmunol Pract. 2017;5:521-15.e.1. https://doi.org/10.1016/j.jaip.2016.12.029

6. Ludman S, Harmon M, Whiting D, du Toit G. Clinical presentation and referral characterisitics of food protein-induced enterocolitis syndrome in the United Kingdom. Ann Allergy Asthma Immunol. 2014;113:290-4. https://doi.org/10.1016/j. anai.2014.06.020

7. Nowak-Wegrzyn A, Chehade M, Groetch ME, Spergel JM, Wood RA, Allen $\mathrm{K}$, et al. International consensus guidelines for the diagnosis and management of food protein-induced enterocolitis syndrome: Executive summary-Workgroup report of the adverse reactions to Foods Committee, American Academy of Allergy, Asthma \& Immunology. J Allergy Clin Immunol. 2017;139:1111-26.e4.

8. Ovadia A, Nahum A, Tasher D, Abiri S, Epov L, Kessel A, et al. Sesame: An unrecognized trigger of food proteininduced enterocolitis syndrome. J allergy Clin Immunol Pract. 2019;7:305-6. https://doi.org/10.1016/j.jaip.2018.05.007

9. Lee E, Barnes EH, Mehr S, Campbell DE. Differentiating acute food protein-induced enterocolitis syndrome from its mimics: A comparison of clinical features and routine laboratory biomarkers. J Allergy Clin Immunol Pract. 2019;7:471-8.e3. https://doi.org/10.1016/j.jaip.2018.10.020

10. Kimura $M$, Ito $\mathrm{Y}$, Shimomura $M$, Morishita $\mathrm{H}$, Meguro $\mathrm{T}$, Adachi $Y$, et al. Cytokine profile after oral food challenge in infants with food protein-induced enterocolitis syndrome. Allergol Int. 2017;66:452-7. https://doi.org/10.1016/j. alit.2016.12.001; https://doi.org/10.1016/j.alit.2016.08.003 